\title{
Four Weeks of Hypoxia Training Improves Cutaneous Microcirculation in Trained Rowers
}

\author{
Zhijun MENG ${ }^{1,2}$, Binghong GAO ${ }^{3}$, Huan $\mathrm{GAO}^{4}$, Peng GE ${ }^{1}$, $\mathrm{Tao}^{4}$, Yuxin WANG \\ ${ }^{1}$ School of Kinesiology, Shanghai University of Sport, Shanghai, China, ${ }^{2}$ Center of Laboratory, \\ Yunnan Institute of Sport Science, Kunming, China, ${ }^{3}$ School of Physical Education and Sport \\ Training, Shanghai University of Sport, Shanghai, China, ${ }^{4}$ Center of Competitive Sports, Shanghai \\ Institute of Sport Science, Shanghai, China
}

Received April 2, 2019

Accepted June 6, 2019

Epub Ahead of Print August 19, 2019

\begin{abstract}
Summary
Hypoxia training can improve endurance performance. However, the specific benefits mechanism of hypoxia training is controversial, and there are just a few studies on the peripheral adaptation to hypoxia training. The main objective of this study was to observe the effects of hypoxia training on cutaneous blood flow (CBF), hypoxia-inducible factor (HIF), nitric oxide (NO), and vascular endothelial growth factor (VEGF). Twenty rowers were divided into two groups for four weeks of training, either hypoxia training (Living High, Exercise High and Training Low, $\mathrm{HHL}$ ) or normoxia training (NOM). We tested cutaneous microcirculation by laser Doppler flowmeter and blood serum parameters by ELISA. HHL group improved the $\mathrm{VO}_{2 \text { peak }}$ and power at blood lactic acid of $4 \mathrm{mmol} / \mathrm{l}\left(\mathrm{P}_{4}\right)$ significantly. The CBF and the concentration of moving blood cells (CMBC) in the forearm of individuals in the $\mathrm{HHL}$ group increased significantly at the first week. The HIF level of the individuals in the HHL group increased at the fourth week. The NO of HHL group increased significantly at the fourth week. In collusion, four weeks of $\mathrm{HHL}$ training resulted in increased forearm cutaneous blood flow and transcutaneous oxygen pressure. $\mathrm{HHL}$ increases rowers' $\mathrm{NO}$ and VEGF, which may be the mechanism of increased blood flow. The increased of $\mathrm{CBF}$ seems to be related with improving performance.
\end{abstract}

\section{Key words}

Hypoxia training • NO • VEGF • Microcirculation • CBF

\section{Corresponding author}

B. Gao, School of Physical Education and Sport Training,
Shanghai University of Sport, Shanghai, China. E-mail: gaobinghong@126.com

\section{Introduction}

Elite athletes have utilized hypoxia training for several years to improve performance (Dufour et al. 2006, Sinex and Chapman 2015). Hypoxia training is conducted by nitrogen dilution or oxygen filtration, simulating high altitudes with low oxygen. Athletes use many different methods of hypoxia training (Living High and Training High, Living Low and Training High, Living High and Training Low, and similar methods), to optimize performance (Wilber 2007). In order to maintain training intensity and experience enough hypoxia stimulation, Living High, Exercise High and Training Low (HHL) is considered a superior method for elite athletes. HHL is a modified training program to increase body tolerance to hypoxia and strengthen cardiopulmonary functions (Chapman et al. 1998, Xu et al. 2015).

However, the objective benefits of hypoxia training are controversial (Gore et al. 1998, Henderson et al. 2001, de Paula and Niebauer 2012). The original method of hypoxia training was designed to increase erythrocyte volume and ultimately to enhance sea level peak oxygen uptake $\left(\mathrm{VO}_{2 \text { peak }}\right)$ and endurance performance (Gore et al. 2006, Garvican-Lewis et al. 2013, Ramos-Campo et al. 2015). Indeed, the acclimatization to high altitude results in central and 
peripheral adaptations that improve oxygen delivery and utilization (Levine and Stray-Gundersen 1997, GarvicanLewis et al. 2013). However, there is substantial evidence showing that improvements in endurance performance at sea level can be obtained through altitude exposure via nonhematological mechanisms, including increases in mitochondrial efficiency, muscle $\mathrm{pH}$ buffer capacity, and mitochondrial uncoupling protein content within the skeletal muscle (Gore et al. 2007).

The microcirculation is associated with hypoxia adaptation (Ovadia-Blechman et al. 2015, Treml et al. 2018). Hypoxia causes cutaneous vasodilation and robust increase in cutaneous blood flow in healthy humans (Simmons et al. 2007, Lawley et al. 2014). Intermittent hypoxia training had greater positive effect on hemodynamics, microvascular endothelial function, and work capacity of untrained healthy men (Shatilo et al. 2008). However, the issue of how a hypoxia stimulus influences the microcirculation and microcirculatory blood flow is still debating and under investigated (Rowell et al. 1982, Simmons et al. 2007, Siebenmann et al. 2017, Treml et al. 2018). Paparde et al. (2015) found that acute systemic hypoxia causes sympathetic stimulation to heart which results in increased heart rate and larger cardiac output, and which could be the reason of forearm skin blood flow increase in acute systemic hypoxia. One might assume - as also written in the scientific literature - that in hypoxia a decrease in oxygen delivery to the cells resulted in a vasodilation of the capillaries in order to enhance blood flow in the microcirculation (Delashaw and Duling 1988). The role of the cutaneous microcirculation is to provide the supply of oxygen and various nutrients and to remove waste products of muscle metabolism. Acute systemic wholebody hypoxia leads to increased diameters of arterioles and venules due to the action of adenosine mediated by nitric oxide (NO), which is one of the endothelium- dependent relaxing factors released by the vascular endothelium and mediates vasodilation. Muscle in chronically hypoxic rats had larger diameters of capillaries and higher capillary density, which helped maintain oxygen supply to muscle fibers despite low values of oxygen in arterial blood (Hudlicka 2011). Also, vascular endothelial growth factor (VEGF) plays a vital role in the growth and differentiation of vascular cells as well as lymphatic endothelial cells in hypoxia condition (Bloor 2005, Vital et al. 2014, Xie et al. 2014, Boos et al. 2018).

Some studies have found the augment of cutaneous blood flow in hypoxia, but data in trained athletes and effect of prolonged hypoxia accommodation are sparse. Therefore, the purpose of this study was to conduct a controlled study of trained rowers training in hypoxia to examine whether four-week hypoxia training could improve the cutaneous microcirculation and the underlying mechanisms. We hypothesized that hypoxia training could improve the rowers' cutaneous microcirculation by vasodilation and angiogenesis.

\section{Material and Methods}

\section{Subjects}

Twenty male rowers who had no altitude or hypoxia training experience were recruited from the Shanghai Rowing Team, and divided into either the HHL group (HHL, $\mathrm{n}=12$ ) or the normoxia training group (NOM, $n=12$, but four rowers quit because of injuries). Participant characteristics are presented in Table 1. The study protocol was approved by the Ethics Commission of Shanghai University of Sport. All participants provided written informed consent before participating. This study is in accordance with the Declaration of Helsinki (2000) of the World Medical Association.

Table 1. Characteristics of study participants.

\begin{tabular}{lcc}
\hline Group & HHL & NOM \\
\hline$N$ & 12 & 8 \\
Age (years) & $18.7 \pm 2.0$ & $16.2 \pm 1.3$ \\
Height (cm) & $185.9 \pm 5.2$ & $188.3 \pm 6.2$ \\
Mass (kg, pre) & $77.8 \pm 6.1$ & $78.7 \pm 13.4$ \\
Mass (kg, post) & $75.6 \pm 6.3$ & $77.9 \pm 13.2$ \\
Body fat (\%, pre) & $12.4 \pm 3.1$ & $19.1 \pm 4.9$ \\
Bodyfat (\%, post) & $10.6 \pm 3.6$ & $17.5 \pm 5.2$ \\
\hline
\end{tabular}




\section{Training program}

The participants used the HHL/NOM program for four weeks. HHL group slept daily and trained six days per week in normobaric hypoxia (2500-3000 m). Additionally, they did sprint training three times per week at sea level. The hypoxic condition was achieved by TOSMA (Berlin, Germany). NOM group slept and trained daily at sea level. The training volume and intensity of the two groups were similar (Table 2).

Table 2. Hypoxia training (HHL) and normoxia training (NOM) program.

\begin{tabular}{|c|c|c|c|c|c|}
\hline & Group & $\begin{array}{c}\text { Sleeping } \\
\text { altitude (m) }\end{array}$ & $\begin{array}{c}\text { Training } \\
\text { altitude (m) }\end{array}$ & $\begin{array}{c}\text { Training } \\
\text { volume }(\mathbf{k m})\end{array}$ & Objectives of training \\
\hline \multirow{2}{*}{ Week 1} & HHL & 2500 & 2500 & 262 & $\begin{array}{c}\text { Adapt to hypoxia training, large } \\
\text { training volume }\end{array}$ \\
\hline & NOM & 100 & 100 & 250 & $\begin{array}{c}\text { Endurance training to improve } \\
\text { aerobic capacity }\end{array}$ \\
\hline \multirow{2}{*}{ Week 2} & HHL & 3000 & 3000 & 260 & Maintain training volume \\
\hline & NOM & 100 & 100 & 252 & Maintain training volume \\
\hline \multirow{2}{*}{ Week 3} & HHL & 3000 & 3000 & 245 & Increase training intensity \\
\hline & NOM & 100 & 100 & 238 & Increase training intensity \\
\hline \multirow{2}{*}{ Week 4} & HHL & 3000 & 3000 & 190 & $\begin{array}{l}\text { Decrease training volume and } \\
\text { prepare for test after intervention }\end{array}$ \\
\hline & NOM & 100 & 100 & 225 & $\begin{array}{l}\text { Decrease training volume and } \\
\text { prepare for test after intervention }\end{array}$ \\
\hline
\end{tabular}

\section{Experimental protocol}

Forearm and leg cutaneous blood flow (CBF) was monitored using a laser Doppler flowmeter (PeriFlux6000, Perimed, Sweden) at room temperature $\left(22{ }^{\circ} \mathrm{C}\right)$ with the subject in a lying position. We tested the forearm and leg blood flow and also the blood flow when exposed to localized heating to $44{ }^{\circ} \mathrm{C}$ for $3 \mathrm{~min}$. Microvascular reactivity (MVR) was evaluated from the maximal post-occlusive reactive hyperemia (PORH) following 3-min forearm ischemia produced by cuff inflation $(200 \mathrm{~mm} \mathrm{Hg})$. Similar procedures have been used by other investigators (Lenasi and Strucl 2004, Shatilo et al. 2008, Tew et al. 2010). Blood pressure was measured by brachial auscultation. $\mathrm{SPO}_{2}$ and heart rate were measured by a handheld pulse oximeter (NONIN, 9500, USA). The blood flow was measured four times: baseline, at the end of the first week, the third week, and post-HHL.

\section{Measurement of $\mathrm{VO}_{2}$ peak and maximum power output}

$\mathrm{VO}_{2 \text { peak }}$ tests were conducted before and after the intervention using an incremental rowing ergometer (Concept 2 Model D, USA) protocol via a portable metabolic analyzer (COSMED K5, Italy). Participants started the protocol with 4-minute stages until exhaustion. The test began with each participant exercising at a $500 \mathrm{~m}$ split time of $1 \mathrm{~min} 56 \mathrm{~s}$. Thereafter, the split time was decreased by $4 \mathrm{~s}$ each stage until the participant reached volitional exhaustion. The $500 \mathrm{~m}$ split time of each stage has been calculate to Watt in Table 3. When the participant reached exhaustion, the max power output (MPO) was recorded.

\section{Measurement of P4}

Subjects performed an incremental test of 5 stages, each of 4-minute duration on rowing ergometer (Concept 2 Model D, USA). The 4-minute stages were separated by 30 -second breaks for blood sampling to test blood lactic acid (EKF c-line, Germany). The power at blood lactic acid of $4 \mathrm{mmol} / \mathrm{l}\left(\mathrm{P}_{4}\right)$ is calculate by quadratic polynomial (Microsoft Excel, USA) (Pardono et al. 2008, Gregg et al. 2010). The polynomial trend line was used because of the high correlation coefficient of determination (r-squared value) between the data and trend line. 
Table 3. Incremental rowing ergometer protocol.

\begin{tabular}{lccc}
\hline Stage & Time (min) & Power $(\mathbf{W})$ & Stroke rate (per minute) \\
\hline 1 & 4 & 224 & 18 \\
2 & 4 & 249 & 20 \\
3 & 4 & 278 & 22 \\
4 & 4 & 311 & 24 \\
5 & 4 & 350 & 26 \\
\hline
\end{tabular}

\section{Measurement of blood serum}

Ten milliliter of blood was collected four times, before HHL, at the second week, at the fourth week, and post HHL. Serum samples were stored at $-80{ }^{\circ} \mathrm{C}$ for later analysis. Hypoxia-inducible factor (HIF), NO, and VEGF were determined with ELISA kits (Wksu-BIO, China) on a Multiskan FC (Thermo, USA). To ensure accuracy, all blood parameters for ELISA used duplicate tubes. The average intra-assay $\mathrm{CV}(\%)$ is $3.8 \%$ and average interassay $\mathrm{CV}(\%)$ is $6.2 \%$. All results were calculated using the SkanIt software (Windows, 5.0).

\section{Timing of measurements}

During one training cycle (1 week), the rowers trained from Monday to Saturday morning, and rest on Saturday afternoon and Sunday. So, the blood test was performed on Monday morning, namely after 1 day and a half rest. We tested blood flow all day on Sunday, because 20 subjects need a long time to complete the test.

\section{Data analysis}

Laser Doppler data were stored in a computer for offline analysis with signal-processing software (Perisoft for Windows 2.5.5; Perimed AB). Skin blood flow responses were defined as follows: (1) baseline, i.e. the arithmetic mean of the fifth and sixth minutes, perfusion unit (PU); (2) the lowest and highest blood flow of PORH; (3) plateau, i.e. the arithmetic mean of the last 2 min of heating at $44{ }^{\circ} \mathrm{C}$; and (4) skin blood flow data (recorded in arbitrary perfusion units; PU). The baseline perfusion unit was divided by the mean arterial pressure (in millimeters of mercury) to give cutaneous vascular conductance (CVC; in PU per millimeter of mercury) (Lawley et al. 2014).

Data were analyzed using SPSS 25.0 (IBM). The Kolmogorov-Smirnov test was used to establish normality of the data. The differences between HHL and NOM were analyzed using a general linear model for repeated measures (normally distributed values) or linear mixed model for repeated measures (abnormally distributed values). The interaction of group by time was evaluated to examine time effect in responses to the intervention. And different times in HHL/NOM were analyzed using a Wilcoxon signed-rank test for abnormally distributed data. Significance was accepted at $p<0.05$, with a trend of significance at $0.05<p<0.1$. All normally distributed values are expressed as mean \pm standard deviation, and all abnormally distributed values are expressed as the interquartile range, median $\left(\mathrm{P}_{25}, \mathrm{P}_{75}\right)$. For effect size, the partial eta squared statistic was calculated, and $0.01,0.06$, and 0.14 were interpreted as small, medium, and large effect sizes, respectively (Richardson 2011).

\section{Results}

In order to establish that HHL can improve participants' cutaneous microcirculation, we tested the blood flow of the forearm and thigh and some blood indicators of vessel vasodilatation and angiogenesis.

As shown in Table 4, general linear model with repeated measurement variance analysis showed a significant time by group interaction on $\mathrm{VO}_{2 \text { peak }}$ $\left(p=0.017, \quad \eta^{2}=0.136\right), \quad \mathrm{P}_{4}\left(p=0.157, \quad \eta^{2}=0.115\right)$, MPO $\left(p=0.253, \eta^{2}=0.048\right)$ So, the hypoxia intervention gave a large-medium effect on $\mathrm{VO} 2_{\text {peak }}$ and $\mathrm{P}_{4}$. HHL group improved the $\mathrm{VO}_{2 \text { peak }}$ significantly $(5553.1 \pm 457.1$ vs. $6217.0 \pm 463.6 \mathrm{ml} / \mathrm{min}), p<0.01$. However, the NOM group showed little change of $\mathrm{VO}_{2 \text { peak }}(4984.9 \pm 498.3$ vs. $5134.8 \pm 788.3 \mathrm{ml} / \mathrm{min}), \quad p=0.677$. The HHL group improved the MPO significantly $(342.9 \pm 15.8$ vs. $358.4 \pm 18.5 \mathrm{~W}, p=0.039)$, but NOM showed little change of maximum power output $(316.6 \pm 23.5$ vs. $322.4 \pm 35.5 \mathrm{~W}, p=0.52)$. And also, $\mathrm{P}_{4}$ appeared in a similar trend. The HHL group improved the $\mathrm{P}_{4}$ significantly $(262.8 \pm 12.5$ vs. $281.5 \pm 12.8 \mathrm{~W}), p<0.01$. 
$\mathrm{P}_{4}$ of NOM group increased form 233.0 \pm 25.9 to $241.9 \pm 36.4 \mathrm{~W}, p=0.157$.

As shown in Table 5, there was a statistically significant difference in $\mathrm{SPO}_{2}$ and transcutaneous oxygen pressure $\left(\mathrm{TcPO}_{2}\right)$ between groups. This was identified as determined by repeated measure linear mixed models, $p<0.01$. Two related samples in a non-parametric test showed that blood flow and concentration of moving blood cells (CMBC) in the forearm of HHL subjects increased significantly at the first week, but these parameters in the thigh and the NOM group did not increase. The lowest and highest blood flow of PORH both increased at the first week $(0.05<p<0.1)$. At the third week, the HHL group's resting blood flow and CMBC of the forearm were lower than in the first week but higher than pretraining. The velocity of blood flow decreased at the first week.

Table 4. The $\mathrm{VO}_{2 \text { peak, }} \mathrm{MPO}$ and $\mathrm{P}_{4}$ of rowers.

\begin{tabular}{lccccccc}
\hline & \multicolumn{2}{c}{ HHL } & & NOM & & IE & ES \\
& Baseline & Post & Baseline & Post & $\boldsymbol{\eta}^{2}$ \\
\hline $\mathrm{PO}_{2}$ peak $(\mathrm{ml} / \mathrm{min})$ & $5553.1 \pm 457.1$ & $6217.0 \pm 463.6^{*}$ & $4984.9 \pm 498.3$ & $5134.8 \pm 788.3$ & 0.017 & 0.136 \\
$\mathrm{MPO}(\mathrm{W})$ & $342.9 \pm 15.8$ & $358.4 \pm 18.6^{*}$ & $316.6 \pm 23.5$ & $322.4 \pm 35.5$ & 0.253 & 0.048 \\
$P_{4}(\mathrm{~W})$ & $262.8 \pm 12.5$ & $281.5 \pm 12.8^{*}$ & $233.0 \pm 25.9$ & $241.9 \pm 36.4$ & 0.442 & 0.115 \\
\hline
\end{tabular}

As shown in Table 6, erythropoietin (EPO) and HIF of HHL subjects increased at the second week $(p>0.05)$, and HIF of HHL subjects also increased at the fourth week $(0.05<p<0.1)$. The NO of HHL subjects increased at the fourth week significantly; while endothelial NO synthase (eNOS) did not show significant changes. Prostaglandin I2 (PGI2) of HHL subjects also increased during HHL but not significantly. Nevertheless, this PGI2 may help to increase the blood flow. Endothelin (ET) of HHL increased at the second week $(p>0.05)$. At the fourth week and post-training, VEGF in the HHL group had a higher value compared to the baseline $(0.05<p<0.1)$, but VEGF receptor (VEGFR) in the HHL group showed little change during hypoxia training.

\section{Discussion}

The purpose of this study was to investigate whether four weeks of HHL can improve participants' microcirculation function, EPO levels, and red blood cell levels. The primary findings of this study are the following. (1) HHL improves blood flow and forearm $\mathrm{TcPO}_{2}$. (2) Importantly, at the different stages of HHL training, the function of microvessels differs, suggesting that HHL can improve vasodilation and increase angiogenesis, but participants need a long time to experience enough hypoxia in HHL. (3) HHL increases rowers' NO and VEGF, which may be the mechanism of increased blood flow.

These results suggest that at the early stage of HHL, vasoconstriction may be dominant. However, when rowers experience more and more hypoxia, vasodilation and angiogenesis may play a key role in their skin blood flow. NO, ET, PGI2 and VEGF are all related to vascular function and angiogenesis.

The principal finding of our study is that the effect of 4 weeks of HHL on microvascular function has a timing effect. The effect of HHL on microcirculation may be dependent on two factors, hypoxia and training. There have been controversies about the change in the microvascular function (vasoconstriction and/or vasodilation) during hypoxia. Some reports have demonstrated in untrained healthy men that intermittent hypoxia training had significant positive effects on cutaneous perfusion and microvascular function (Shatilo et al. 2008). Paparde et al. (2015) demonstrated that acute hypoxia $\left(\mathrm{PO}_{2}=12 \%\right)$ increases forearm skin blood flow, but the reason for this may be that sympathetic stimulation to the heart results in an increased heart rate and more massive cardiac output. Heart rate variability suggests that there are significant increases in sympathetic responses in acute hypoxia. So, blood flow increases despite vasoconstriction (Paparde et al. 2015). Simmons et al. (2007) have suggested that increased adrenalin production does not inhibit the vasodilation of blood vessels in hypoxia. This is consistent with the results of ET and $\mathrm{HR}$ in our study. Although ET 
increased at the second week, blood flow also increased, which may be due to increased eNOS and PGI2. We found similar results from rowers after four weeks HHL training, but only in their forearms. This is because the thighs are the primary working muscle of rowers, and they may be affected by training status and fatigue. Also, PORH reserve capacity is an indication of endothelial function (Lenasi and Strucl 2004).

Table 5. Characteristics of microcirculation-related parameters.

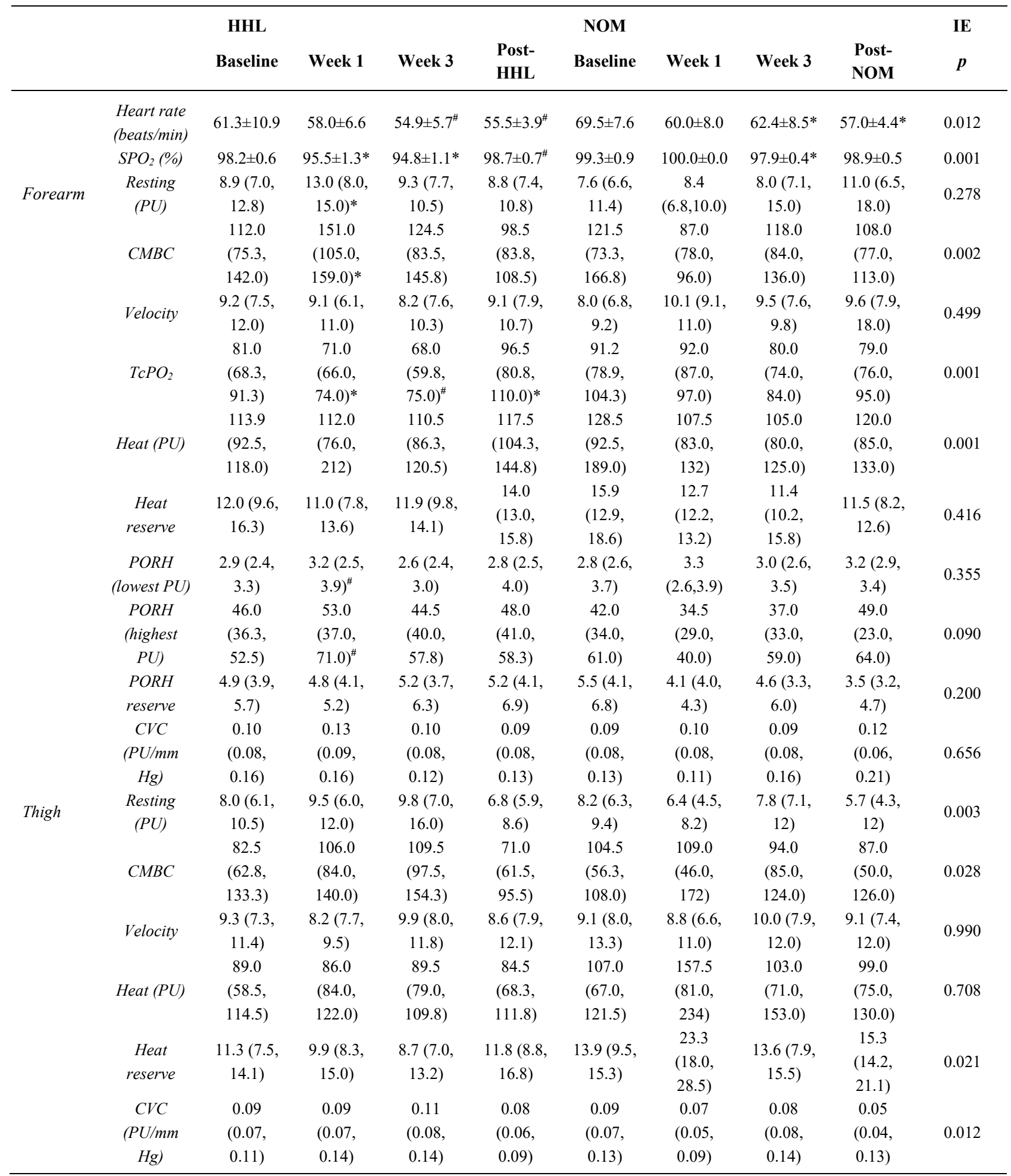

${ }^{*} p<0.05$ versus baseline; ${ }^{*} 0.05<p<0.1$ vs. baseline. Heat reserve: (heat $\left.\mathrm{PU}\right) /($ resting $\mathrm{PU}) ; \mathrm{PORH}$ reserve: $\mathrm{PORH}$ (highest PU)/(resting $\mathrm{PU})$; IE: time by group interaction effect. 
Table 6. Characteristics of HIF, NO, and VEGF-related parameters.

\begin{tabular}{|c|c|c|c|c|c|c|c|c|c|}
\hline & HHL & & & & NOM & & & & Interaction \\
\hline & Baseline & Week 2 & Week 4 & Post-HHL & Baseline & Week 2 & Week 4 & $\begin{array}{l}\text { Post- } \\
\text { NOM }\end{array}$ & $p$ \\
\hline$E P O$ & $\begin{array}{c}10.4(8.8 \\
13.1)\end{array}$ & $\begin{array}{c}12.7(10.1 \\
13.5)\end{array}$ & $\begin{array}{c}11.1(10.1 \\
13.0)\end{array}$ & $\begin{array}{c}6.5(4.9 \\
9.9)^{*}\end{array}$ & $\begin{array}{c}9.0(6.3 \\
10.1)\end{array}$ & $\begin{array}{c}9.1(5.9 \\
12.6)\end{array}$ & $\begin{array}{c}8.7(6.4 \\
10.7)\end{array}$ & $\begin{array}{c}8.6(5.1 \\
10.0)\end{array}$ & 0.008 \\
\hline$H I F(p g / m l)$ & $\begin{array}{c}27.0(19.8 \\
66.4)\end{array}$ & $\begin{array}{c}27.7(15.4 \\
75.5)\end{array}$ & $\begin{array}{c}31.1(25.4 \\
66.2)^{\#}\end{array}$ & $\begin{array}{c}30.0(26.6 \\
53.5)\end{array}$ & $\begin{array}{c}42.6(29.8, \\
135.0)\end{array}$ & $\begin{array}{c}43.1(27.5 \\
84.5)\end{array}$ & $\begin{array}{c}48.4(37.3 \\
123.0)\end{array}$ & $\begin{array}{c}68.1(35.2 \\
201.6)\end{array}$ & 0.075 \\
\hline$N O(\mu \mathrm{mol} / \mathrm{l})$ & $\begin{array}{c}0.05(0.04 \\
0.15)\end{array}$ & $\begin{array}{c}0.06(0.04 \\
0.19)\end{array}$ & $\begin{array}{c}0.08(0.06 \\
0.14)^{*}\end{array}$ & $\begin{array}{c}0.08(0.05 \\
0.13)\end{array}$ & $\begin{array}{c}0.10(0.06 \\
0.21)\end{array}$ & $\begin{array}{c}0.09(0.05 \\
0.19)\end{array}$ & $\begin{array}{c}0.10(0.08 \\
0.29)\end{array}$ & $\begin{array}{c}0.11(0.06 \\
0.32)\end{array}$ & 0.247 \\
\hline $\begin{array}{l}\text { eNOS } \\
(I U / m l)\end{array}$ & $\begin{array}{c}2.2(1.5 \\
6.5)\end{array}$ & $\begin{array}{c}2.5(1.5 \\
8.6)\end{array}$ & $\begin{array}{c}3.3(1.7 \\
6.3)\end{array}$ & $\begin{array}{c}3.0(1.9 \\
6.5)\end{array}$ & $\begin{array}{c}4.4(2.5 \\
8.7)\end{array}$ & $\begin{array}{c}4.3(1.9 \\
8.3)\end{array}$ & $\begin{array}{c}3.8(2.6 \\
12.6)\end{array}$ & $\begin{array}{c}6.1(2.5 \\
24.6)\end{array}$ & 0.078 \\
\hline$E T(p g / m l)$ & $\begin{array}{c}10.2(6.9 \\
29.3)\end{array}$ & $\begin{array}{c}12.9(6.8 \\
46.3)\end{array}$ & $\begin{array}{c}10.4(8.0 \\
20.5)\end{array}$ & $\begin{array}{c}9.8(6.3 \\
17.7)\end{array}$ & $\begin{array}{c}16.8(10.2 \\
39.8)\end{array}$ & $\begin{array}{c}18.8(9.0, \\
38.6)\end{array}$ & $\begin{array}{c}15.9(10.4 \\
37.0)^{*}\end{array}$ & $\begin{array}{c}12.7(7.8, \\
36.7)\end{array}$ & 0.101 \\
\hline $\begin{array}{l}P G I 2 \\
(\mathrm{mIU} / \mathrm{ml})\end{array}$ & $\begin{array}{c}8.9(6.1 \\
22.6)\end{array}$ & $\begin{array}{c}9.5(5.0 \\
38.0)\end{array}$ & $\begin{array}{c}9.9(7.0 \\
22.6)\end{array}$ & $\begin{array}{c}9.2(6.2 \\
20.1)\end{array}$ & $\begin{array}{c}15.7(9.1 \\
39.7)\end{array}$ & $\begin{array}{c}18.9(8.6, \\
50.8)\end{array}$ & $\begin{array}{c}20.8(14.2 \\
55.0)\end{array}$ & $\begin{array}{c}15.6(11.3 \\
46.5)\end{array}$ & 0.364 \\
\hline $\begin{array}{l}V E G F \\
(p g / m l)\end{array}$ & $\begin{array}{c}13.5(8.9 \\
39.2)\end{array}$ & $\begin{array}{c}14.3(8.6, \\
43.6)\end{array}$ & $\begin{array}{c}17.6(10.7 \\
45.5)^{\#}\end{array}$ & $\begin{array}{c}17.0(11.6 \\
42.0)^{\#}\end{array}$ & $\begin{array}{c}15.3(11.8, \\
39.0)\end{array}$ & $\begin{array}{c}18.8(11.2 \\
34.5)\end{array}$ & $\begin{array}{c}28.7(18.4 \\
81.3)\end{array}$ & $\begin{array}{c}26.5(13.9 \\
85.8)\end{array}$ & 0.124 \\
\hline $\begin{array}{l}\text { VEGFR } \\
(n g / m l)\end{array}$ & $\begin{array}{c}1.6(0.9 \\
3.1)\end{array}$ & $\begin{array}{c}1.6(0.7 \\
4.0)\end{array}$ & $\begin{array}{c}1.7(1.0 \\
3.3)\end{array}$ & $\begin{array}{c}1.7(1.0 \\
2.6)\end{array}$ & $\begin{array}{c}1.5(1.0 \\
6.0)\end{array}$ & $\begin{array}{c}2.3(1.5 \\
4.4)\end{array}$ & $\begin{array}{c}2.3(1.6 \\
6.1)\end{array}$ & $\begin{array}{c}2.2(1.1 \\
6.2)\end{array}$ & 0.494 \\
\hline
\end{tabular}

${ }^{*} p<0.05$ versus baseline; ${ }^{*} 0.05<p<0.1$ vs. baseline.

In this study, we found that HHL rowers increase their PORH reserve capacity, which means that their endothelial function is improved by hypoxia training. Montero et al. (2015) found that microvascular dilator function of endurance athletes was enhanced more than that of age-matched untrained healthy subjects. Maione et al. (2015) reported oxygen uptake kinetics during the constant load exercise sub-anaerobic threshold are highly sensitive to endothelial function in muscular microcirculation. Therefore, it is speculated that long-term endurance training may improve microvascular health. This is consistent with Boegli's study, as he found that improved microvascular health is induced by NO (Boegli et al. 2003). Bloor et al. (2005) have suggested that exercise and training can increase angiogenesis by VEGF, but the inducing factor may be HIF because exercise can also upregulate VEGF and HIF transcription. Gustafsson et al. (2002) took muscle biopsy samples from subjects after single leg movements and found VEGF mRNA expression was significantly raised and was related to HIF mRNA. So, exercise results in muscle ischemia and hypoxia, which induce HIF and increase VEGF expression (Gustafssonet al. 2002). Therefore, HIF may be the core factor in NO and VEGF expression during hypoxia and exercise.

Nitric oxide, and VEGF play a significant role in the regulation of baseline, evoking blood flow during hypoxia (Takuwa et al. 2010, Shafighi et al. 2012).
Viboolvorakul and Patumraj 2014) found that eight weeks of exercise training improved microvascular changes and hypoperfusion closely associated with the upregulation of VEGF and eNOS. Asano et al. (1998) found the timing effect of serum VEGF at high altitude (1886 m), where VEGF decreased ten days after the start of altitude training, but reached a peak 19 days later $(46.0 \pm 14.6 \mathrm{pg} / \mathrm{ml})$. Their result of VEGF is higher than that observed in our study, which may be because of the difference between altitude and simulated hypoxia (HHL). However, Morici et al. (2013) found that people living at sea level had lower plasma VEGF 3-4 days after arriving at $5050 \mathrm{~m}$. It is generally accepted that long-term hypoxia exposure can increase the density of capillaries, which can lead to a maximum diffusion of oxygen. Of course, different hypoxia levels may also be essential for angiogenesis.

Our results are consistent with the hypothesis that hypoxia training improves rowers' cutaneous microcirculation, and the mechanism may be vasodilation and angiogenesis, related to NO and VEGF. However, the benefit has a timing effect, and changes in functionality and mechanisms are not synchronized. Based on NO and VEGF, vasodilatation and angiogenesis appear to persist until the end of hypoxia training.

In conclusion, in addition to the traditional research on the hematologic system in hypoxia training, we have found that four weeks of HHL training increases 
forearm blood flow and improves endothelial function. HHL increases rowers' NO and VEGF, which may be the mechanism of increased blood flow. The increased of $\mathrm{CBF}$ seems to be one mechanism for improving performance. However, more studies are needed to confirm this.

\section{Limitations}

The study documents a practical example of 4 weeks of HHL use by elite rowers and includes a control group. However, the number of control group presents a limitation, which is 4 rowers' quit because of injury. Although we tried to manage the difference in training between HHL and NOM, training is one key factor influencing blood flow, NO, VEGF, and related markers. One of the limitations about the study is lack of hypoxia group (without training) to interpret the training factor. The other Limitation of the study is lack of traditional hematological data used to describe the course of adaptation to the hypoxic training in rowers. In the future, we will expand our research scope and observation in our coming studies.

\section{Conflict of Interest}

There is no conflict of interest.

\section{Acknowledgements}

We want to thank all the volunteers who participated in the study. The financial support for the study was provided by Shanghai Association for Science and Technology (NO. 15490503300) and supported by Shanghai Key Lab of Human Performance (Shanghai University of Sport (NO. 11DZ2261100).

\section{References}

ASANO M, KANEOKA K, NOMURA T, ASANO K, SONE H, TSURUMARU K, YAMASHITA K, MATSUO K, SUZUKI H, OKUDA Y: Increase in serum vascular endothelial growth factor levels during altitude training. Acta Physiol Scand 162: 455-459, 1998.

BLOOR CM: Angiogenesis during exercise and training. Angiogenesis 8: 263-271, 2005.

BOEGLI Y, GREMION G, GOLAY S, KUBLI S, LIAUDET L, LEYVRAZ PF, WAEBER B, FEIHL F: Endurance training enhances vasodilation induced by nitric oxide in human skin. J Invest Dermatol 121: 1197-1204, 2003.

BOOS CJ, LAMB CM, MIDWINTER M, MELLOR A, WOODS DR, HOWLEY M, STANSFIELD T, FOSTER M, O'HARA JP: The effects of acute hypoxia on tissue oxygenation and circulating alarmins in healthy adults. Physiol Res 67: 935-943, 2018.

CHAPMAN RF, STRAY-GUNDERSEN J, LEVINE BD: Individual variation in response to altitude training. $J$ Appl Physiol (1985) 85: 1448-1456, 1998.

DE PAULA P, NIEBAUER J: Effects of high altitude training on exercise capacity: fact or myth. Sleep Breath 16: 233-239, 2012.

DELASHAW JB, DULING BR: A study of the functional elements regulating capillary perfusion in striated muscle. Microvasc Res 36: 162-171, 1988.

DUFOUR SP, PONSOT E, ZOLL J, DOUTRELEAU S, LONSDORFER-WOLF E, GENY B, LAMPERT E, FLUCK M, HOPPELER H, BILLAT V, METTAUER B, RICHARD R, LONSDORFER J: Exercise training in normobaric hypoxia in endurance runners. I. Improvement in aerobic performance capacity. J Appl Physiol (1985) 100: 1238-1248, 2006.

GARVICAN-LEWIS LA, CLARK SA, POLGLAZE T, MCFADDEN G, GORE CJ: Ten days of simulated live high:train low altitude training increases Hbmass in elite water polo players. Br J Sports Med 47 (Suppl 1): i70-i73, 2013.

GORE CJ, CLARK SA, SAUNDERS PU: Nonhematological mechanisms of improved sea-level performance after hypoxic exposure. Med Sci Sports Exerc 39: 1600-1609, 2007.

GORE CJ, HAHN A, RICE A, BOURDON P, LAWRENCE S, WALSH C, STANEF T, BARNES P, PARISOTTO R, MARTIN D, PYNE D: Altitude training at 2690m does not increase total haemoglobin mass or sea level VO2max in world champion track cyclists. J Sci Med Sport 1: 156-170, 1998. 
GORE CJ, RODRIGUEZ FA, TRUIJENS MJ, TOWNSEND NE, STRAY-GUNDERSEN J, LEVINE BD: Increased serum erythropoietin but not red cell production after 4 wk of intermittent hypobaric hypoxia (4,000-5,500 m). J Appl Physiol (1985) 101: 1386-1393, 2006.

GREGG JS, WYATT FB, KILGORE JL: Determination of ventilatory threshold through quadratic regression analysis. J Strength Cond Res 24: 2512-2515, 2010.

GUSTAFSSON T, KNUTSSON A, PUNTSCHART A, KAIJSER L, NORDQVIST AC, SUNDBERG CJ, JANSSON E: Increased expression of vascular endothelial growth factor in human skeletal muscle in response to shortterm one-legged exercise training. Pflugers Arch 444: 752-759, 2002.

HENDERSON KK, CLANCY RL, GONZALEZ NC: Living and training in moderate hypoxia does not improve VO2 max more than living and training in normoxia. $J$ Appl Physiol (1985) 90: 2057-2062, 2001.

HUDLICKA O: Microcirculation in skeletal muscle. Muscles Ligaments Tendons J 1: 3-11, 2011.

LAWLEY JS, OLIVER SJ, MULLINS PG, MACDONALD JH, MOORE JP: Prolonged (9 h) poikilocapnic hypoxia $(12 \%$ O2) augments cutaneous thermal hyperaemia in healthy humans. Exp Physiol 99: 909-920, 2014.

LENASI H, STRUCL M: Effect of regular physical training on cutaneous microvascular reactivity. Med Sci Sports Exerc 36: 606-612, 2004.

LEVINE BD, STRAY-GUNDERSEN J: "Living high-training low": effect of moderate-altitude acclimatization with low-altitude training on performance. J Appl Physiol (1985) 83: 102-112, 1997.

MAIONE D, CICERO AF, BACCHELLI S, COSENTINO ER, DEGLI ESPOSTI D, MANNERS DN, RINALDI ER, ROSTICCI M, SENALDI R, AMBROSIONI E, BORGHI C: The VO(2)-on kinetics in constant load exercise sub-anaerobic threshold reflects endothelial function and dysfunction in muscle microcirculation. Physiol Res 64: 807-819, 2015.

MONTERO D, WALTHER G, DIAZ-CANESTRO C, PYKE KE, PADILLA J: Microvascular dilator function in athletes: a systematic review and meta-analysis. Med Sci Sports Exerc 47: 1485-1494, 2015.

MORICI G, BONANNO A, LICCIARDI A, VALLI G, PASSINO C, BONARDI D, LOCOROTONDO N, PROFITA M, PALANGE P, COGO A, BONSIGNORE MR: Plasma leptin and vascular endothelial growth factor (VEGF) in normal subjects at high altitude (5050 m). Arch Physiol Biochem 119: 219-224, 2013.

OVADIA-BLECHMAN Z, MEILIN A, RABIN N, ELDAR M, CASTEL D: Noninvasive monitoring of peripheral microcirculatory hemodynamics under varying degrees of hypoxia. Respir Physiol Neurobiol 216: 23-27, 2015.

PAPARDE A, PLAKANE L, CIRCENIS K, AIVARS JI: Effect of acute systemic hypoxia on human cutaneous microcirculation and endothelial, sympathetic and myogenic activity. Microvasc Res 102: 1-5, 2015.

PARDONO E, SOTERO RDA C, HIYANE W, MOTA MR, CAMPBELL CS, NAKAMURA FY, SIMOES HG: Maximal lactate steady-state prediction through quadratic modeling of selected stages of the lactate minimum test. J Strength Cond Res 22: 1073-1080, 2008.

RAMOS-CAMPO DJ, MARTINEZ-SANCHEZ F, ESTEBAN-GARCIA P, RUBIO-ARIAS JA, CLEMENTESUAREZ VJ, JIMENEZ-DIAZ JF: The effects of intermittent hypoxia training on hematological and aerobic performance in triathletes. Acta Physiol Hung 102: 409-418, 2015.

RICHARDSON JTE: Eta squared and partial eta squared as measures of effect size in educational research. Educat Res Rev 6: 135-147, 2011.

ROWELL LB, FREUND PR, BRENGELMANN GL: Cutaneous vascular response to exercise and acute hypoxia. J Appl Physiol Respir Environ Exerc Physiol 53: 920-924, 1982.

SHAFIGHI M, OLARIU R, BRUN C, FATHI AR, DJAFARZADEH S, JAKOB SM, HUNGER RE, BANIC A, CONSTANTINESCU MA: The role of androgens on hypoxia-inducible factor (HIF)-1alpha-induced angiogenesis and on the survival of ischemically challenged skin flaps in a rat model. Microsurg 32: 475-481, 2012.

SHATILO VB, KORKUSHKO OV, ISCHUK VA, DOWNEY HF, SEREBROVSKAYA TV: Effects of intermittent hypoxia training on exercise performance, hemodynamics, and ventilation in healthy senior men. High Alt Med Biol 9: 43-52, 2008. 
SIEBENMANN C, KERAMIDAS ME, RUNDQVIST H, MIJWEL S, COWBURN AS, JOHNSON RS, EIKEN O: Cutaneous exposure to hypoxia does not affect skin perfusion in humans. Acta Physiol (Oxf) 220: 361-369, 2017.

SIMMONS GH, MINSON CT, CRACOWSKI JL, HALLIWILL JR: Systemic hypoxia causes cutaneous vasodilation in healthy humans. J Appl Physiol (1985) 103: 608-615, 2007.

SINEX JA, CHAPMAN RF: Hypoxic training methods for improving endurance exercise performance. $J$ Sport Health Sci 4: 325-332, 2015.

TAKUWA H, MATSUURA T, BAKALOVA R, OBATA T, KANNO I: Contribution of nitric oxide to cerebral blood flow regulation under hypoxia in rats. J Physiol Sci 60: 399-406, 2010.

TEW GA, KLONIZAKIS M, SAXTON JM: Effects of ageing and fitness on skin-microvessel vasodilator function in humans. Eur J Appl Physiol 109: 173-181, 2010.

TREML B, KLEINSASSER A, STADLBAUER KH, STEINER I, PAJK W, PILCH M, BURTSCHER M, KNOTZER H: Cutaneous microvascular blood flow and reactivity in hypoxia. Front Physiol 9: 160, 2018.

VIBOOLVORAKUL S, PATUMRAJ S: Exercise training could improve age-related changes in cerebral blood flow and capillary vascularity through the upregulation of VEGF and eNOS. Biomed Res Int 2014: 230791, 2014.

VITAL TM, STEIN AM, DE MELO COELHO FG, ARANTES FJ, TEODOROV E, SANTOS-GALDUROZ RF: Physical exercise and vascular endothelial growth factor (VEGF) in elderly: A systematic review. Arch Gerontol Geriatr 59: 234-239, 2014.

WILBER RL: Application of altitude/hypoxic training by elite athletes. Med Sci Sports Exerc 39: 1610-1624, 2007.

XIE HC, HE JP, ZHU JF, LI JG: Expression of HIF-1alpha and VEGF in skeletal muscle of plateau animals in response to hypoxic stress. Physiol Res 63: 801-805, 2014.

XU Y, HU Y, REN Z, YI L: Delta-aminolevulinate synthase 2 polymorphism is associated with maximal oxygen uptake after living-high exercise-high training-low in a male Chinese population. Int J Clin Exp Med 8: 21617-21622, 2015. 